25th Anniversary Commemorative Meeting at Pugwash, Canada, call on the Pugwash Movement and the scientists of the world to intensify their efforts and to rededicate their energies and activities to the abolition of the threat of nuclear war and to the establishment of a just and secure world order.

\section{Nuclear Power is Considered Essential to Development}

Nuclear power is considered essential to meeting the growing demands for electricity, particularly in developing nations, where the needs are greatest. It 'may make a positive contribution to the quality of life'- even to the extent of decreasing the 'rate of degradation of the environment.' And, contrary to popular belief, the harm that is caused to health and the environment by its waste products or through nuclear accidents--such as in the US case of the Three Mile Island core-melt - is 'low relative to other sources,' and certainly no greater than that of the other energy-producing fuels, such as oil and coal.

These statements are made in a report published recently by the International Atomic Energy Agency (IAEA) and the World Health Organization (WHO), which addresses "environmental issues that may be encountered by states that choose to develop the nuclear power option.' Entitled Nuclear Power, the Environment and $\mathrm{Man}^{*}$, the publication's main point is that nuclear power is a viable alternative, and a necessary complement to fossil fuels.

Oil, coal, and natural gas, are now the conventional sources of energy - with oil and gas making up $70 \%$ of the world's total energy consumption - but their use has always depended upon a balancing of benefits and risks, the report points out: 'If the world is to develop, with goods and welfare shared more widely and more equitably, high energy demands will require the utilization of a wide variety of appropriate sources of energy, including nuclear power.' Another reason is that oil and gas 'may be exhausted in the next few decades,' and coal, 'while plentiful, is often difficult to mine and distribute.' Although there are about 2,100 coal deposits known throughout the world, the eleven largest are located in just three countries - the Federal Republic of Germany, the Soviet Union, and the United States.

\section{Unprecedented Demand for Electricity}

It is the growth in urban populations, particularly those that make up the "mammoth conglomerations now forming in the developing countries,' which is creating the unprecedented demand for energy. In India, the annual energy consumption in urban areas per caput, the report says by way of example, "is almost seven times that of the rural communities.'

While energy is essential for 'food production, for domestic and industrial heating or cooling, for electrical production, for transport, and for many other processes,' it is needed most to generate electricity. According to figures cited, the population of Mexico City is expected

* Edited by a 7-members' board under the chairmanship of Sir Edward Pochin, this publication of 196 pages, complete with charts, tables, and photographs of nuclear plants around the world, is available for 200 Austrian Schillings - from IAEA, Division of Publications, Vienna, Austria.-Ed. to rise to 30 millions by the year 2000 , and that of Bombay, Cairo, Jakarta, and Seoul, to between 15 and 20 millions each. There are also expected to be 400 cities of more than a million inhabitants each in the developing world.

As a result of such rampant urbanization, the report says, the share of electricity in total energy is expected to double, from $16 \%$ to $32 \%$, in the Third World by the end of this century. For developed countries, it is expected to increase from $31 \%$ to $46 \%$. 'In some countries,' the report adds, 'no alternative exists which can replace nuclear power as a means of meeting future energy demands.'

\section{Renewable and Nuclear Sources of Energy}

What are called 'renewable sources of energy'-as, for instance, energy from the oceans, from the sun, and from wind-are also being exploited to help to satisfy the world hunger for fuel. But, with the exception of hydro-energy, these "have been slow in developing because of the high level of capital expenditure required,' the report of the two agencies says. Even the development of hydro-power is "limited to those geographical areas where conditions are suitable for building reservoirs.' As for solar energy, 'its use has not developed as rapidly as had been hoped,' the report admits: 'It is increasingly used for heating family houses rather than for electrical production.'

All told, there are 272 nuclear power reactors now in operation and 236 more under construction, or a total of 508 , in 30 countries, developed and otherwise. Of the overall total, 154 are in the United States, where there are 75 in operation and 79 under construction; there are 60 in the Soviet Union ( 35 and 25 , respectively), 56 in France (30 and 26), and 42 in the United Kingdom ( 32 and 10).

With little in the way of sources of conventional energy of their own, Belgium, Bulgaria, Finland, France, Japan, Sweden, and Switzerland, are already relying heavily on nuclear energy for electricity. 'The share of nuclear power for the generation of electricity in those countries ranges up to $30 \%$ or more, and may grow to 70 or $80 \%$ by the year 2000,' the report says. While most of the plants - 475-are in industrialized countries, 33 are in 9 developing countries. The Republic of Korea, for instance, has 1 in operation and 8 under construction; India has 4 and 4 ; and China has 3 and 3, respectively.

Nuclear plants generate electricity from the heat that it produced following the splitting of the nuclei of atoms of heavy materials. Uranium is the principal fuel. Yet another advantage of nuclear power is that is uses less fuel than other sources. 'About 200 tonnes of uranium fuel are required to operate a $1-G W(e)$ - one gigawatt of electricity - power plant for a year,' the report says, 'whereas a fossil-fuelled plant of this capacity requires about 2 million tonnes of anthracite coal or 9 million barrels of oil.'

\section{Wastes and an Accident}

Even though nuclear wastes are regarded as a major problem, the report points out that disposal in "underground repositories' has been under study for more than two decades. For high-level radioactive wastes, the method most generally accepted is burial, from 500 to 1,000 metres deep, in 'stable geological formations' - as for instance salt deposits or crystalline rock. According to estimates cited, 'less than 800 hectares of a salt deposit would be adequate to dispose of all high-activity ... 
wastes generated by the nuclear industry in the United States until the end of this century.'

Another possibility that is under study is disposal of radioactive wastes in the ocean sea-bed, "as the deep ocean is poor in resources that are likely to be exploited by Man.'

The core-melt at the Three Mile Island nuclear plant in Pennsylvania is described in the report as a "loss-ofcoolant' accident triggered by equipment failure and compounded by an 'operator error.' But the report points out that the plant's 'containment building performed as designed in containing the radioactive materials released from the core.' Thus the amount 'escaping into the environment was very low, about 2.5 parts in ten million of the iodine.*

According to the IAEA/WHO report: 'The continuous concern for safety addresses the entire range of possible accidents - including the potential for large-consequence accidents, although these are considered unlikely.' In a foreword to the publication, the DirectorsGeneral of WHO and IAEA state that nuclear power 'is a technology whose hazardous effects are well understood and controlled,' being 'a fact of life that must be looked at objectively and rationally.'

\section{Peter Ozorio \\ Division of Public Information World Health Organization \\ 1211 Geneva 27 \\ Switzerland.}

* We hope soon to publish an account of this celebrated event, by a member of the President's investigating team. Meanwhile our publication of the present comment should not be construed as indicating any lack on our part either of abhorrence at the existing build-up of nuclear weapons or of recognition of the risks of proliferation of peaceful uses that can be turned to belligerent ends.--Ed.

\section{Fact-sheet on Tropical Rain-forests}

\section{Introduction}

According to UN/FAO estimates, tropical rain-forests cover some 550 million hectares of the globe. In the last 20-30 years Man's interaction with these forest ecosystems has increased dramatically, not only in extent but also in intensity of impacts. Tropical forests are being severely modified or destroyed in response to pressures from the rapidly-expanding populations of tropical countries, their striving for economic development, and an accelerated search for new timber resources by industrial temperate-region countries. Improved technology, commerce patterns, and infrastructure development, have widely increased the effective impact of wood harvesting and land clearing activities. Most investigators agree that, if present trends continue and effective conservation measures are not implemented, most of the still-existing forests of the tropics will be destroyed or replaced by degraded communities by the end of the century.

Tropical rain-forests comprise uniquely rich biotic communities which are particularly sensitive to disturbance. The understanding of how to manage the many types of rain-forest in order to maintain their long-term productivity and character is limited or non-existent; the potential values of rain-forest, and the benefits provided to mankind in direct economic terms and in contributions to maintaining a satisfactory human environment, have barely been explored. As a consequence, there are few restraints on the exploitation of the rain-forest resources of the Amazon Basin, coastal Central America, Congo Basin, Malay Peninsula, New Guinea, and numerous smaller areas of rain-forest occurrence.

\section{Tropical Rain-forest Ecosystems}

This 'ecosystem type' or biome has been called with good reason the richest and most exuberant expression of life on land, and is characterized by an exceptional diversity of plant and animal forms, species, and interactions. On some sites tropical rain-forests have provided continuous cover since the flowering plants evolved, developing over millennia in the relatively non-stressful environment of the tropics, where temperature and moisture fluctuations are the lowest of almost anywhere on Earth, and where plants grow apace. It is literally the genetic cradle of evolution and indeed constitutes our richest gene-pool This outstanding diversity (50-200 species of higher plants per hectare as compared with perhaps 20 species per hectare in a rich temperate forest) also proves to be a liability. For it means that in a given area there are few individuals of any one tree species, and heavy exploitation of one or a few species can therefore quickly lead to their local extinction.

Primary rain-forest species are in general not aggressive, and thus tend to be quite vulnerable to disturbance. Moreover, regionally-limited distribution (endemism) is common for these plant and animal species of tropical rain-forests. Because of the characteristics of diversity and limited occurrence, destruction of the tropical rainforest can often cause species to become rare or even extinct. Moreover rain-forest ecosystems, when once seriously disturbed, return to their former state only very gradually if at all (see below).

\section{Values of Tropical Rain-forests}

Currently, the chief direct economic values of tropical rain-forest are found in the production of wood and the use of their plants and animals for food, drugs, raw materials (hides, fibres, gums and resins, etc.), medical research, and breeding. There are, however, many tangible and intangible values which have important significance, but which are often overlooked, such as the following:

Scientific value:- The tropical rain-forests are not only an extremely important and scarcely-explored source of new products, but also constitute a major study-area for the expansion of knowledge about plant and animal interrelationships. They are the world's major gene-pool and are often considered the evolutionary cradle of terrestrial life; there is therefore an imperative need to slow the rate of disappearance of primary tropical rain-forests before these scientific values are irretrievably lost to society.

Effect on climate:-Certain aspects of climate are influenced by the presence or removal of rain-forest. There is scientific concern that large-scale removal of tropical rain-forests could result in a cooling of the tropics, with resultant shifts in world wind and rainfall patterns. More research is needed, but there is already much empirical evidence that clearing of rain-forest has led to local changes in rainfall that are so marked as to disrupt established land-uses of the area concerned. 